Review

\title{
Where does brain neural activation in aesthetic responses to visual art occur? Meta-analytic evidence from neuroimaging studies
} \author{
D.W. Zaidel ${ }^{\mathrm{d}}$ \\ a Department of Psychology, "Sapienza" University of Rome, Via dei Marsi, 78, 00185 Rome, Italy \\ b Neuropsychology Unit, IRCCS Fondazione Santa Lucia, Rome, Italy \\ c Department of Life, Health and Environmental Sciences, L'Aquila University, L'Aquila, Italy \\ ${ }^{\mathrm{d}}$ Department of Psychology, University of California, Los Angeles (UCLA), Los Angeles, CA, USA
}

M. Boccia ${ }^{\mathrm{a}, \mathrm{b}, *}$, S. Barbetti ${ }^{\mathrm{a}, \mathrm{b}}$, L. Piccardi $^{\mathrm{b}, \mathrm{c}}$, C. Guariglia $^{\mathrm{a}, \mathrm{b}}$, F. Ferlazzo $^{\mathrm{a}}$, A.M. Giannini ${ }^{\mathrm{a}}$,

\section{A R T I C L E I N F O}

\section{Article history:}

Received 5 June 2015

Received in revised form 31 August 2015

Accepted 2 September 2015

Available online 24 November 2015

\section{Keywords:}

Brain and art

Neuroaesthetics

Beauty and brain

Neuroimaging

fMRI

Beauty meta-analysis

\begin{abstract}
A B S T R A C T
Here we aimed at finding the neural correlates of the general aspect of visual aesthetic experience (VAE) and those more strictly correlated with the content of the artworks. We applied a general activation likelihood estimation (ALE) meta-analysis to $47 \mathrm{fMRI}$ experiments described in 14 published studies. We also performed four separate ALE analyses in order to identify the neural substrates of reactions to specific categories of artworks, namely portraits, representation of real-world-visual-scenes, abstract paintings, and body sculptures. The general ALE revealed that VAE relies on a bilateral network of areas, and the individual ALE analyses revealed different maximal activation for the artworks' categories as function of their content. Specifically, different content-dependent areas of the ventral visual stream are involved in VAE, but a few additional brain areas are involved as well. Thus, aesthetic-related neural responses to art recruit widely distributed networks in both hemispheres including content-dependent brain areas of the ventral visual stream. Together, the results suggest that aesthetic responses are not independent of sensory, perceptual, and cognitive processes.
\end{abstract}

(c) 2015 Elsevier Ltd. All rights reserved.

\section{Contents}

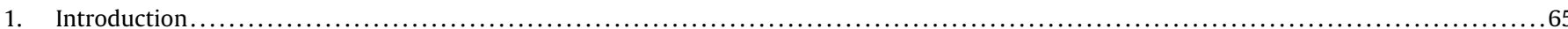

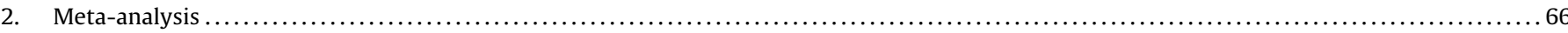

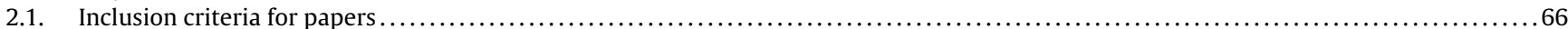

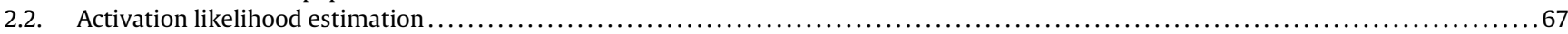

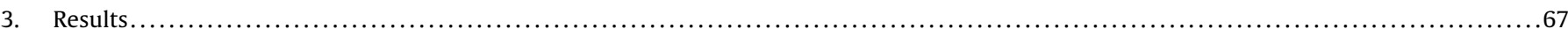

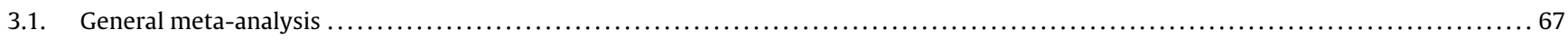

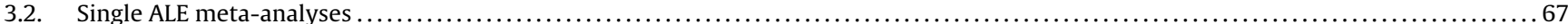

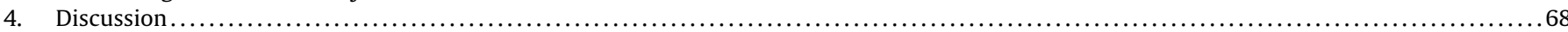

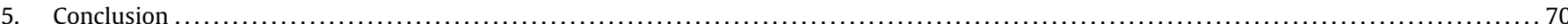

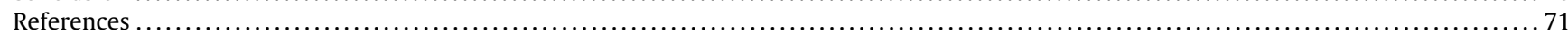

\footnotetext{
* Corresponding author at: Sapienza University of Rome; IRCCS Fondazione Santa Lucia, Department of Psychology, via dei Marsi 78, 00185 Rome, Italy. Tel.: +39 0651501117; fax: +390651501213.

E-mail address: maddalena.boccia@uniroma1.it (M. Boccia).
}

\section{Introduction}

An artwork can be described as an object perceived as "skillful and creative expressions of human experience, in which the manner of creation is not primarily driven by any other function" (Hagtvedt and Patrick, 2008; pp. 380), but it is also an unequivocal expression of intentionality and communication. Intentions play a pivotal role in producing works of art and clearly differentiate artworks from other types of human creations. Earlier theories 
about the mind and aesthetic experience can be found both in Kant and Schopenhauer (Kant, 1790; Schopenhauer, 1969). In Schopenhauer's theory, in particular, the notion of aesthetic attitude saw its emergence. Aesthetic attitude has been proposed to require an intentional shift from an automatic visuo-perceptual processing to an "aesthetic state of mind", more explicitly directed to the sensory experience (Cupchik and Winston, 1996; Cupchik, 1992) and to reflect a unique, emotionally coloured, self-transcending subject-object relationship (Marković, 2012).

In the past decade a large body of research assessing the neural underpinnings of visual aesthetic experience (VAE) of artworks through the use of functional neuroimaging (Nadal, 2013; Vartanian et al., 2013) has been published. One of the major goals of this field is to reveal the neural network underlying the aesthetic experience of visual artworks (Boccia et al., 2015; Cela-Conde et al., 2011; Di Dio et al., 2007; Kirk et al., 2009a; Vartanian and Goel, 2004; Vessel et al., 2012). The overall findings report that aesthetic experience requires a distributed network of activation in regions associated with different functions (e.g., sensory, cognitive, motoric) (Di Dio and Gallese, 2009), and this suggests that artrelated aesthetic experience taps into a neural system, rather than into a single neural region (Cela-Conde and Ayala, 2014; Vartanian and Skov, 2014).

Functional neuroimaging studies of visual aesthetic experience (VAE) of artworks has found that occipito-temporal regions involved in processing early and intermediate visual features such as orientation, shape and colour, as well as object recognition are maximally active (Vartanian and Skov, 2014). Non-art studies using fMRI have shown that the ventral occipito-temporal regions, also known as the ventral visual stream(VVS), are selectively responsive to separate visual categories, namely whole faces in the fusiform face area (Kanwisher et al., 1997), places in the parahippocampal place area (Epstein et al., 1999), and whole bodies in the extrastriate body area (Brandman and Yovel, 2014; Downing et al., 2001) and in the fusiform body area (Brandman and Yovel, 2014; Taylor et al., 2007). Of interest is whether or not the contents of visually categorized artworks would similarly activate these content-specialized areas of the VVS.

Other brain regions have also been found to be active when subjects view artworks. Different zones within the orbitofrontal cortex have been found to be differentially involved (Ishizu and Zeki, 2013; Kawabata and Zeki, 2004). The anterior cingulate cortex has been found to be involved in the general aspect of VAE regardless of the category of content (Boccia et al., 2015; Pöppel et al., 2013; Yeh et al., 2015) and it has been also found to be activated during aesthtic experience across different sensory modalities (Brown et al., 2011). The anterior cingulate cortex and the orbitofrontal cortex are examples of brain regions underlying the interaction between cognition and emotion during the evaluation of sensory information (Pessoa, 2008; Rolls and Grabenhorst, 2008). In particular, the orbitofrontal cortex directly receives input from late visual areas (such as that along the inferior temporal cortex, which is part of the VVS). Thus, the orbitofrontal region is extremely well positioned to tune perceptual processing in visual areas, and underlie emotional evaluation of art. Interestingly, aesthetic experience has recently been seen as the result of the interaction between intentional (i.e., top-down) orienting of attention, in the lateral prefrontal cortex, and bottom-up constructive facilitation, in the superior parietal lobe (Cupchik et al., 2009).

Chatterjee and Vartanian (2014) (Chatterjee, 2004) developed a theoretical model of the cognitive and affective processes involved in VAE, namely a series of information-processing stages. First, all of the elementary visual features of artworks are processed like all other visual objects; second, attentional processes redirect information processing to salient visual properties, such as colour, shape, and composition, by means of the fronto-parietal attentional network; third, the attentional network modulates processing within the attributional areas of the ventral visual stream; fourth, feedback and feed-forward processes, linking attentional and category-specific circuits (e.g., in the VVS), enhance the experience of the visual stimuli. Finally, in most cases emotional systems are also involved. The category-specific areas of the VVS (i.e., face, place, body) have been recently hypothesized to serve as neural triggers for pervasive effects of aesthetic experiences (Chatterjee et al., 2009).

Cela-Conde et al. (2013) proposed that the whole aesthetic experience consists mainly of two distinct cognitive events, which take place at different time spans: an initial general appraisal of the aesthetic qualities (i.e., the perception of a visual stimulus as beautiful or not), which the authors call "aesthetic appreciation sensu stricto" and a delayed appraisal of detailed aspects of the aesthetic experience (i.e., whether it is interesting or original), which the authors call "aesthetic appreciation sensu lato". The aesthetic appreciation sensu stricto has been found to rely mainly on a network of areas encompassing occipital and frontal regions, while the aesthetic experience sensu lato mainly correspond to the activation of the default mode network (DMN) (Cela-Conde et al., 2013). These results, together with others (Munar et al., 2012; Vessel et al., 2012), support the idea that the aesthetic experience is the result of coordination of different cognitive processes associated with the activation of interconnected regions of a widespread neural network.

In the present study we tested the hypothesis that categoryspecific regions in the VVS contribute to VAE as function of the content of the art, through a meta-analytic approach based on activation likelihood estimation (ALE) analysis. This method allows performing coordinate-based meta-analyses of fMRI data that condenses the wealth of neuroimaging findings into meaningful patterns. We applied a general ALE meta-analysis to identify neural substrates underpinning general aspects of VAE as well as four separate ALE analyses to different categories of artworks, namely painted portraits, representations of real-world visual scenes, abstract paintings, and body sculptures. Based on previous observations (Brown et al., 2011; Vartanian and Skov, 2014), we hypothesized that viewing visual art activates early occipital visual areas and the VVS, as well as medial and lateral frontal regions involved in emotional and affective processes.

\section{Meta-analysis}

\subsection{Inclusion criteria for papers}

A systematic method was adopted to review the literature. The search was carried out using PubMed, a free digital archive of biomedical and life sciences journal literature in which all articles using fMRI are reported. Relevant articles were identified through searches using the following string: "neuroaesthetic" $<\mathrm{OR}>$ "neuroesthetic" < OR $>$ "aesthetic" < OR $>$ "esthetic" < AND $>$ "fMRI" $<$ NOR $>$ "PET" $<$ NOR $>$ "EEG" $<$ NOR $>$ "patients". A total of 45 papers were found.

Our a-priori inclusion criteria for papers were: (1) Inclusion of whole-brain analysis performed using functional magnetic resonance imaging (fMRI); thus, we excluded positron emission tomography (PET) studies, electrophysiology studies and papers that reported only results from ROI analysis. (2) Provision of coordinates of activation foci, either in Montreal Neurological Institute (MNI) or Talairach reference space. (3) All participants in the studies had to be young and healthy. (4) All neuroimaging studies had to include a visuo-perceptual control condition to exclude all activations that were not directly connected to VAE. (5) The experimental tasks required participants to make an aesthetic judgment 
Table 1

Papers included in the meta-analysis.

\begin{tabular}{|c|c|c|c|c|c|c|c|}
\hline \multirow[t]{2}{*}{ Paper/Study } & \multirow[t]{2}{*}{$\mathrm{N}$} & \multicolumn{6}{|c|}{ Number of experiments } \\
\hline & & All & Body & Scene & Portrait & Abstract & Miscellaneous \\
\hline \multirow{2}{*}{ Di Dio et al. (2011) } & 32 & 4 & 4 & & & & \\
\hline & 24 & 6 & 6 & & & & \\
\hline Boccia et al. (2015) & 20 & 1 & & & 1 & & \\
\hline Flexas et al. (2014) & 24 & 3 & & 1 & & 1 & 1 \\
\hline Mizokami et al. (2014) & 39 & 2 & & 2 & & & \\
\hline Ishizu and Zeki (2013) & 12 & 4 & & 1 & 1 & & 2 \\
\hline Vessel et al. (2012) & 16 & 2 & & & & & 2 \\
\hline Cupchik et al. (2009) & 16 & 2 & & & & & 2 \\
\hline Di Dio et al. (2007) & 14 & 5 & 5 & & & & \\
\hline Ishizu and Zeki (2011) & 21 & 4 & & & & & 4 \\
\hline Kawabata and Zeki (2004) & 10 & 6 & & 2 & 1 & & 3 \\
\hline Lacey et al., 2011 & 8 & 3 & & & & & 3 \\
\hline Vartanian and Goel (2004) & 12 & 1 & & 1 & & & \\
\hline Kirk et al. (2009a) & 14 & 2 & & & & 2 & \\
\hline Kirk et al. (2009b) & 24 & 2 & & 2 & & & \\
\hline
\end{tabular}

Notes. $\mathrm{N}=$ number of participants in each study.

about artworks. Studies that did not focus on aesthetic experience of visual artworks were excluded from the meta-analysis. (6) Only group studies were included. (7) There could be no pharmacological manipulation. Using these criteria, we selected 14 papers (these studies are summarized in Table 1 ).

\subsection{Activation likelihood estimation}

Activation likelihood estimation (ALE) analyses the probability that a voxel will contain at least one of the activation foci; it is calculated at each voxel and results in a thresholded ALE map. In other words, ALE assesses the overlap between foci by modeling the probability distributions centered at the coordinates of each one (Eickhoff et al., 2009).

A general ALE meta-analysis was performed on the foci derived from the selected studies on VAE (Table 1). The coordinates of the foci were taken from original papers. The general ALE meta-analysis was performed on a total of 47 experiments (335 activation foci, 880 participants) reported in the 14 selected studies (see above for inclusion criteria).

We also performed four separate ALE analyses on different categories of artworks used in the experiments: portraits, representation of real-world visual scenes (i.e., painted representation of complex scenes of local visual environment, such as landscapes, city streets or buildings; Epstein and Kanwisher, 1998), abstract art, and sculptures of the body. As the authors never explicitly stated the category of artwork, two experimenters (M.B. and S.B.) independently classified the studies. Experiments including different categories of paintings were excluded from these analyses. Thus, the data from these experiments were included in the general analysis but not in the individual analyses. Separate ALE analyses were performed on (1) 3 experiments using paintings of portraits (42 participants, 38 activation foci), (2) 9 experiments using paintings of real-world visual scene (194 participants, 46 activation foci), (3) 3 experiments using painted abstract art (52 participants, 13 activation foci) and (4) 15 experiments using photographs of sculptures of the body (342 participants, 130 activation foci).

The ALE meta-analysis was performed using GingerALE 2.3.1 (brainmap.org) with MNI coordinates (Talairach coordinates were automatically converted into MNI coordinates by GingerALE.). In accordance with Eickhoff et al.'s (2009) modified procedure, the ALE values of each voxel in the brain were computed and a test was performed to determine the null distribution of the ALE statistic of each voxel. The Full-Width Half-Maximum (FWHM) value was automatically computed, because this parameter is empirically determined (Eickhoff et al., 2009). The thresholded ALE map was computed using p values from the previous step and a False Discovery Rate (FDR) at the 0.05 level of significance (Tom Nichol's FDR algorithm). Moreover, a minimum cluster size of $200 \mathrm{~mm}^{3}$ was chosen. A cluster analysis was performed on the thresholded map. The ALE results were registered on an MNI-normalized template (brainmap.org) using MRICRO (http://www.mccauslandcenter.sc. edu/mricro/index.html).

\section{Results}

\subsection{General meta-analysis}

The general ALE meta-analysis of VAE revealed clusters of activations in a wide bilateral network of areas (Fig. 1; Table 2) covering areas that encompass the range of occipital to frontal lobes. This network encompassed bilateral inferior occipital gyrus, lingual and parahippocampal gyri, inferior frontal gyrus, anterior cingulate cortex, amygdala and insula. VAE also activated the middle frontal gyrus, fusiform gyrus and precuneus in the right hemisphere, as well as the medial frontal gyrus, precentral gyrus and middle occipital gyrus in the left hemisphere.

\subsection{Single ALE meta-analyses}

To test for the specific engagement of the neural categoryspecific areas in the VVS, we led four ALE analyses: ALE analysis on fMRI experiments of VAE of painted portraits revealed clusters of activation in the right hemisphere (Fig. 2), specifically in the fusiform face area and inferior occipital gyrus as well as in the amygdala.

The ALE analysis on fMRI experiments of VAE of representations of real-world visual scenes revealed clusters of activation in the parahippocampal gyrus, in the place area, retrosplenial cortex and middle temporal gyrus in the right hemisphere as well as in the left lingual gyrus (Fig. 3)

The ALE analysis on fMRI experiments of VAE of abstract paintings revealed cluster of activation in the posterior cingulate cortex bilaterally (Fig. 4).

Finally, the ALE analysis on fMRI experiments of VAE of body sculptures revealed cluster of activation in the bilateral fusiform body areas (but not in the extrastriate areas), supplementary motor areas, inferior frontal gyri (at the boundary with precentral gyri) hippocampi and insula, as well as in the lingual and inferior occipital gyri, inferior frontal gyrus and superior parietal lobule in the right hemisphere (Fig. 5). 


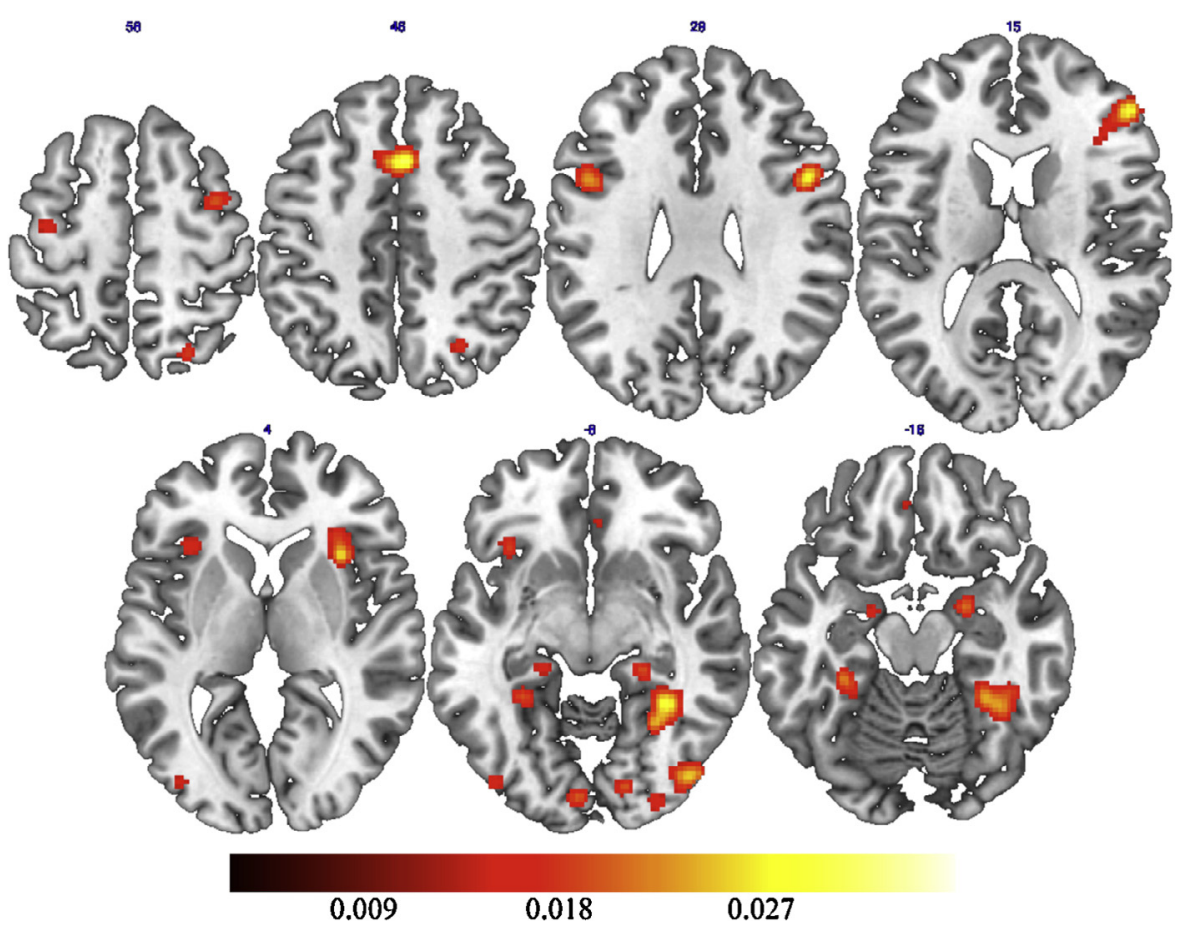

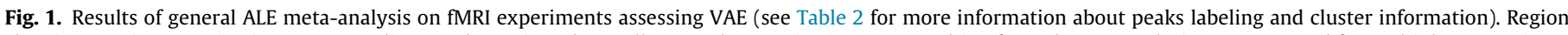

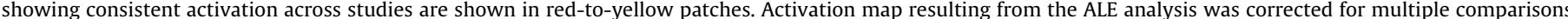

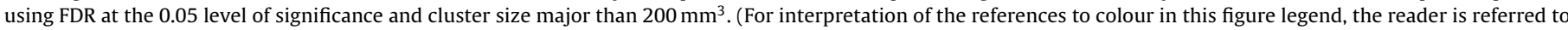
the web version of this article.)

Table 2

Region showing consistent activations across neuroimaging studies of VAE.

\begin{tabular}{|c|c|c|c|c|c|c|c|}
\hline Region & $\mathrm{BA}$ & Hem & Volume $\left(\mathrm{mm}^{3}\right)$ & ALE Value & $x$ & $y$ & $z$ \\
\hline Parahippocampal gyrus & 37 & $\mathrm{R}$ & 5280 & 0.030 & 34 & -48 & -10 \\
\hline Culmen, anterior cerebellum & & $\mathrm{R}$ & & 0.025 & 30 & -40 & -20 \\
\hline Fusiform gyrus & 37 & $\mathrm{R}$ & & 0.023 & 30 & -54 & -8 \\
\hline Middle frontal gyrus & 46 & $\mathrm{R}$ & 3320 & 0.028 & 50 & 38 & 14 \\
\hline Claustrum & & $\mathrm{R}$ & & 0.024 & 32 & 20 & 4 \\
\hline Medial frontal gyrus & 32 & $\mathrm{~L}$ & 2688 & 0.035 & 2 & 16 & 48 \\
\hline Inferior occipital gyrus & 19 & $\mathrm{R}$ & 1768 & 0.029 & 40 & -78 & -4 \\
\hline Parahippocampal gyrus & 36 & $\mathrm{~L}$ & 1552 & 0.024 & -32 & -36 & -18 \\
\hline Parahippocampal gyrus & 37 & $\mathrm{~L}$ & & 0.018 & -30 & -44 & -8 \\
\hline Inferior frontal gyrus & 9 & $\mathrm{~L}$ & 1400 & 0.023 & -46 & 8 & 30 \\
\hline Middle frontal gyrus & 6 & $\mathrm{R}$ & 1288 & 0.028 & 38 & 0 & 54 \\
\hline Insula & 13 & $\mathrm{~L}$ & 1272 & 0.024 & -36 & 22 & -2 \\
\hline Inferior frontal gyrus & 9 & $\mathrm{R}$ & 1232 & 0.028 & 48 & 10 & 30 \\
\hline Precuneus & 7 & $\mathrm{R}$ & 1032 & 0.026 & 24 & -66 & 54 \\
\hline Parahippocampal gyrus & 27 & $\mathrm{R}$ & 1000 & 0.026 & 22 & -32 & -4 \\
\hline Amygdala & & $\mathrm{R}$ & 600 & 0.020 & 22 & -4 & -16 \\
\hline Inferior occipital gyrus & 19 & $\mathrm{~L}$ & 552 & 0.017 & -38 & -82 & 2 \\
\hline Middle occipital gyrus & 18 & $\mathrm{~L}$ & & 0.016 & -42 & -82 & -6 \\
\hline Lingual gyrus & 18 & $\mathrm{R}$ & 536 & 0.019 & 14 & -84 & -6 \\
\hline Lingual gyrus & 18 & $\mathrm{~L}$ & 528 & 0.018 & -6 & -88 & -8 \\
\hline Inferior occipital gyrus & 18 & $\mathrm{R}$ & 528 & 0.018 & 30 & -92 & -4 \\
\hline Anterior cingulate cortex & 32 & $\mathrm{~L}$ & 472 & 0.017 & -4 & 40 & -12 \\
\hline Anterior cingulate cortex & & $\mathrm{R}$ & & 0.013 & 6 & 32 & -6 \\
\hline Parahippocampal gyrus & 27 & $\mathrm{~L}$ & 344 & 0.018 & -20 & -32 & -6 \\
\hline Precentral gyrus & 4 & $\mathrm{~L}$ & 264 & 0.016 & -38 & -12 & 60 \\
\hline Amygdala & & $\mathrm{L}$ & 208 & 0.015 & -18 & -6 & -16 \\
\hline Amygdala & & $\mathrm{L}$ & & 0.013 & -24 & -12 & -14 \\
\hline
\end{tabular}

Notes. BA= Brodmann areas, if applicable; Hem = hemisphere.

\section{Discussion}

Our first aim was to find converging evidence for a neural network for VAE. The results of the general ALE analysis highlighted a network of areas encompassing the range of the occipital to the frontal lobes, and including both category-specific areas of the VVS as well as anterior frontal areas. Further, the results of the single ALE analyses on different categories of visual artworks revealed a neural segregation in the VVS as function of the different contents of the art. The fusiform face area showed greater activation for painted portraits, the parahippocampal place area showed greater activation for representations of real-world visual scenes; the fusiform body area as well as the structures of the limbic lobe, the inferior frontal gyrus, the supplementary motor area and the insula 


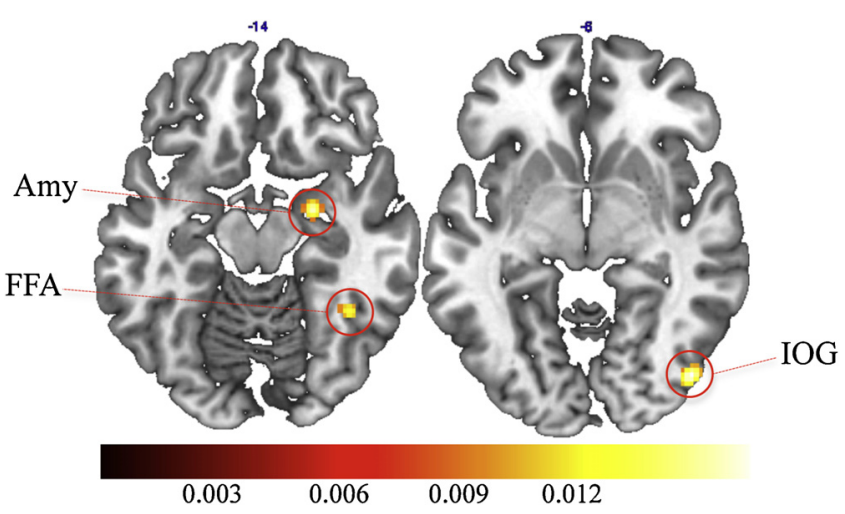

Fig. 2. Results of single ALE meta-analysis on fMRI experiments assessing VAE of portraits. Region showing consistent activation across studies are shown in redto-yellow patches. Activation map was corrected for multiple comparisons using FDR at the 0.05 level of significance and cluster size major than $200 \mathrm{~mm}^{3}$. Notes. $\mathrm{FFA}=$ fusiform face area; Amy = amygdala; IOG = inferior occipital gyrus. (For interpretation of the references to colour in this figure legend, the reader is referred to the web version of this article.)

all showed greater activation for body sculptures. Thus, the results hint that art is not a single entity category, that, in fact, viewing it triggers brain activation depending on the content of the artistic depiction itself.

Several investigations (Vartanian and Skov, 2014, for review) and a recent meta-analysis (Vartanian and Skov, 2014) have reported the aesthetic response contribution of the categoryspecific areas of VVS, and the present study shows, for the first time, converging evidence in greater detail for the involvement of these category-specific areas in VAE, plus other brain regions. Our present results seem to confirm the hypothesis by Chatterjee et al. (2009) that category-specific areas of the VVS (i.e., fusiform face area, parahippocampal place area, and fusiform body area) have specific neural rolls in the pervasive effects of aesthetic experience.

But the total picture of the neural VAE is far from being simple. Representations of real-world visual scenes activate a whole network (parahippocampal gyrus, retrosplenial cortex, the right middle temporal gyrus and the left lingual gyrus) not just the place area of the VVS. The fact that the left lingual gyrus is activated as well should not be surprising given the role it plays in colour knowledge; damage to the gyrus can give rise to colour agnosia (Zaidel, 2005). Some of the activated regions are involved in human navigation and learning new environments (Boccia et al., 2014). Painted portraits activate the amygdala (Ahs et al., 2013), not just the face area of the VVS. Also, body sculptures rely on activation of the

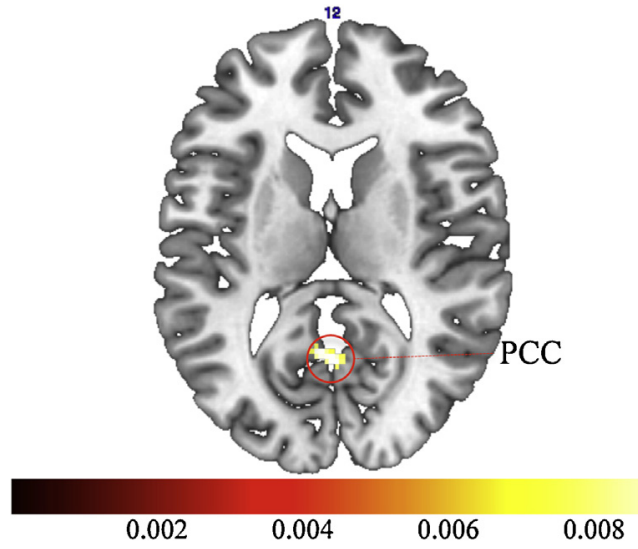

Fig. 4. Results of single ALE meta-analysis on fMRI experiments assessing VAE of abstract paintings. Region showing consistent activation across studies are shown in red-to-yellow patches. Activation map was corrected for multiple comparisons using FDR at the 0.05 level of significance and cluster size major than $200 \mathrm{~mm}^{3}$. Notes. $\mathrm{PCC}=$ posterior cingulate cortex. (For interpretation of the references to colour in this figure legend, the reader is referred to the web version of this article.)

insula, not just the fusiform body area of the VVS (Amoruso, 2011; Kanwisher et al., 1997; Tsakiris et al., 2007). These areas are clearly involved in the pervasive effects of VAE. Interestingly, however, the extrastriate body area was not consistently activated across studies; one would have expected activation particularly upon viewing body sculptures.

Abstract paintings, a category that combines several artisticrelated concepts, on the other hand, did not activate regions within the VVS. We found that VAE of abstract paintings relies mainly on activation of the posterior cingulate cortex, and this suggests a continuum in art contents and differently activated brain areas. Abstract paintings can be highly conceptual despite not being explicitly representational. The significance of activation in the posterior cingulate cortex is that this region is linked to supporting internally-directed cognition, including the retrieval of episodic and semantic memories (Leech and Sharp, 2014); its role in VAE of abstract paintings may be related to processing of internal thoughts (Vessel et al., 2012) rather than to externally guided processing. It would seem, then, that aesthetic responses recruit the same regions recruited by non-art perceptual and cognitive events (Kanwisher et al., 1997; Epstein et al., 1999; Downing et al., 2001; Taylor et al., 2007; Brandman and Yovel, 2014), but since there are infinite ways to depict the contents of visual art, one would expect additional neural areas to be uncovered in future studies. The metaanalysis also showed that the anterior cingulate cortex is involved

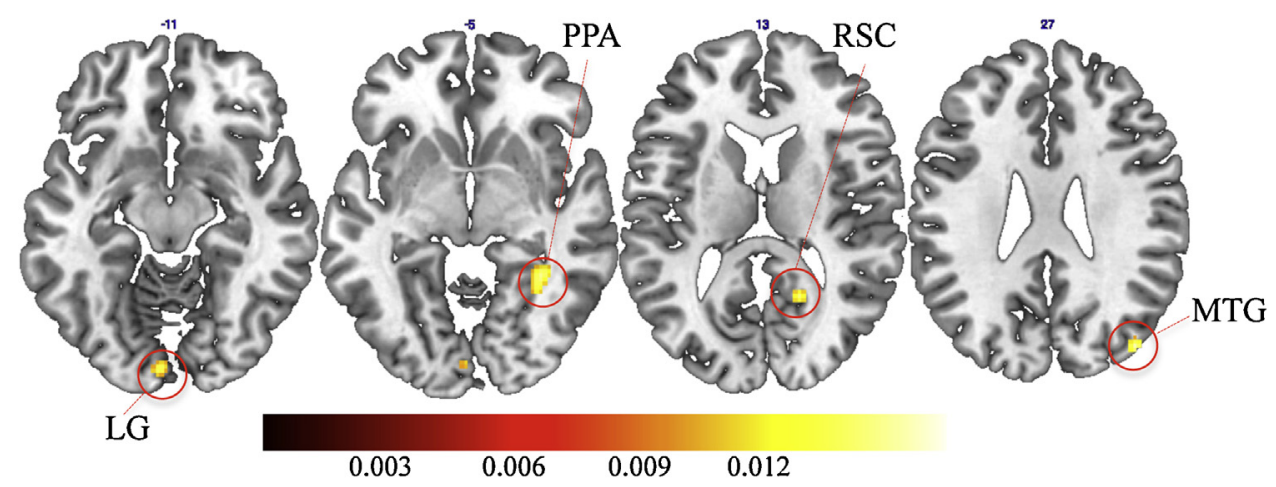

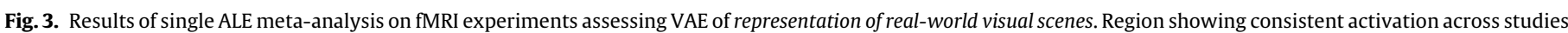

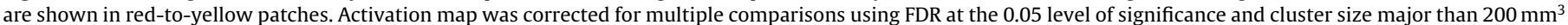

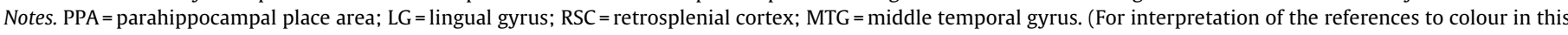
figure legend, the reader is referred to the web version of this article.) 


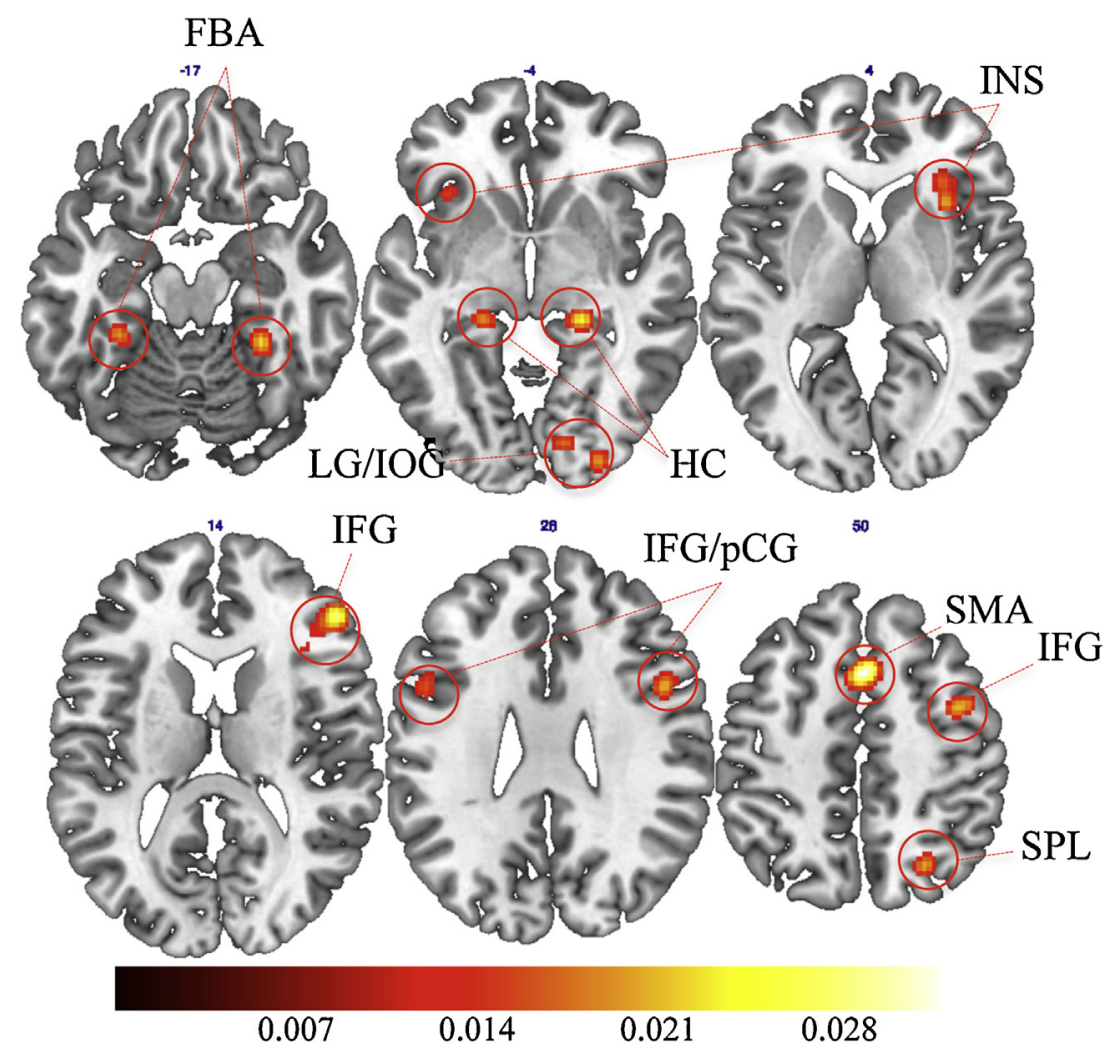

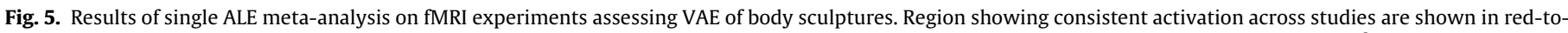

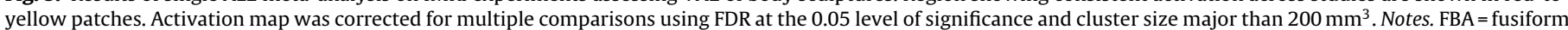

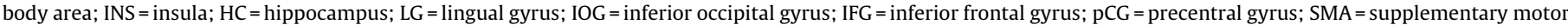
area; $\mathrm{SPL}=$ superior parietal lobe. (For interpretation of the references to colour in this figure legend, the reader is referred to the web version of this article.)

bilaterally. In non-art studies it has been found to be particularly active in explicitly evaluative processes (Cunningham et al., 2004). In art-related studies, it has been linked to the intentional nature of the aesthetic evaluation (Jacobsen et al., 2006). It is considered to be strongly linked to affective processing as well as to functional integration of cognition and emotion (Pessoa, 2008). The general ALE meta-analysis demonstrated that anterior cingulate cortex is consistently activated, suggesting that this structure plays a critical role in aspects of the so-called "aesthetic state of mind", which underlies processing of emotional aspects of aesthetic-related responses and their integration with higher order cognitive evaluation.

In light of the neural model proposed by Cela-Conde et al. (2013), the consistent activation across studies that we found in the anterior cingulate cortex deserves additional considerations. As stated in the Introduction, these authors proposed that "aesthetic appreciation sensu lato", which consists of delayed appraisal of detailed aspects of the aesthetic experience, mainly corresponds to the activation of the so-called default mode network (Cela-Conde et al., 2013). The default mode network has been repeatedly found to be involved in spontaneous cognition and internally focused tasks (Buckner et al., 2008). The anterior cingulate cortex is part of this network (Greicius et al., 2003) and it has been proposed that it serves as a connectivity hub, where cognition and emotion interact to promote evaluation of sensory information (Pessoa, 2008). It may play a pivotal role in coordinating neural processes underlying perceptual, cognitive and emotional responses required for the whole VAE.

The present results inform further neuroimaging research about VAE. It helps in clarifying that art content plays a role in what brain areas are activated and demonstrates that aesthetic experience is not independent from sensory, perceptual, and cognitive processes.
The VAE is interwoven into these processes. Cognitive assessment in aesthetic appreciation has previously been reported by Flexas et al. (2014). The findings here further suggest that clarifications in future research are required especially given the universally wide variety of art that is produced throughout the world. Different neural perceptual processes may be involved with different categories of artworks.

\section{Conclusion}

In the present study we tested the hypothesis that categoryspecific regions in the VVS contribute to VAE as function of the content of the art, and found that viewing visual art activates early occipital visual areas and the VVS, as well as medial and lateral frontal regions involved in emotional and affective processes. Specifically, different content-dependent areas of the VVS are involved as function of the category of content. The present results confirm that a widespread neural network contributes to the aesthetic experience of visual artworks, and this supports the notions that (1) it is represented by widely distributed activated regions, and (2) consists mainly of content-dependent areas of the ventral visual stream (Brown et al., 2011). On the whole, these results suggest that art is a multi-faceted expression of human cognition and as such it recruits the functions of multiple brain regions. It has already been hypothesized that art, a uniquely human activity, did not originate for the purpose of creating mere objects of beauty but rather as a form of communication (Zaidel, 2015). The results of the meta-analyses here confirm that aesthetic reactions to artworks, rather than being mere reactions, are another feature of human cognition with multiple neuroanatomical bases. 


\section{References}

Ahs, F., Davis, F.C., Gorka, A.X., Hariri, A.R., 2013. Feature-based representations of emotional facial expressions in the human amygdala. Soc. Cogn. Affect. Neurosci., http://dx.doi.org/10.1093/scan/nst112, nst112.

Amoruso, L., 2011. Beyond extrastriate body area (EBA) and fusiform body area (FBA): context integration in the meaning of actions. Front. Hum. Neurosci. http://dx.doi.org/10.3389/fnhum.2011.00124.

Boccia, M., Nemmi, F., Guariglia, C., 2014. Neuropsychology of environmental navigation in humans: review and meta-analysis of fMRI studies in healthy participants. Neuropsychol. Rev. 24, 236-251, http://dx.doi.org/10.1007/ s11065-014-9247-8.

Boccia, M., Nemmi, F., Tizzani, E., Guariglia, C., Ferlazzo, F., Galati, G., Giannini, a.M 2015. Do you like Arcimboldo's? Esthetic appreciation modulates brain activity in solving perceptual ambiguity. Behav. Brain Res. 278, 147-154, http://dx.doi. org/10.1016/j.bbr.2014.09.041.

Brandman, T., Yovel, G., 2014. Bodies are represented as wholes rather than their sum of parts in the occipital-temporal cortex. Cereb. Cortex, http://dx.doi.org/ $10.1093 /$ cercor/bhu205.

Brown, S., Gao, X., Tisdelle, L., Eickhoff, S.B., Liotti, M., 2011. Naturalizing aesthetics: brain areas for aesthetic appraisal across sensory modalities. Neuroimage 58 , 250-258, http://dx.doi.org/10.1016/j.neuroimage.2011.06.012.

Buckner, R.L., Andrews-Hanna, J.R., Schacter, D.L., 2008. The brain's default network: anatomy, function, and relevance to disease. Ann. N.Y. Acad. Sci. 1124, 1-38, http://dx.doi.org/10.1196/annals.1440.011.

Cela-Conde, C., Ayala, F., 2014. Brain keys in the appreciation of beauty: a tale of two worlds. Rend. Lincei 25, 277-284, http://dx.doi.org/10.1007/s12210-0140299-8.

Cela-Conde, C.J., Agnati, L., Huston, J.P., Mora, F., Nadal, M., 2011. The neural foundations of aesthetic appreciation. Prog. Neurobiol. 94, 39-48, http://dx. doi.org/10.1016/j.pneurobio.2011.03.003.

Cela-Conde, C.J., García-Prieto, J., Ramasco, J.J., Mirasso, C.R., Bajo, R., Munar, E. Flexas, A., del-Pozo, F., Maestú, F., 2013. Dynamics of brain networks in the aesthetic appreciation. Proc. Natl. Acad. Sci. U.S.A. 110 (Suppl), 10454-10461, http://dx.doi.org/10.1073/pnas.1302855110.

Chatterjee, A., 2004. Prospects for a cognitive neuroscience of visual aesthetics. Bull. Psychol. Arts 4, 56-60.

Chatterjee, A., Thomas, A., Smith, S.E., Aguirre, G.K., 2009. The neural response to facial attractiveness. Neuropsychology 23, 135-143, http://dx.doi.org/10.1037| a0014430.

Chatterjee, A., Vartanian, O., 2014. Neuroaesthetics. Trends Cogn. Sci. 18, 370-375, http://dx.doi.org/10.1016/j.tics.2014.03.003.

Cunningham, W.A., Raye, C.L., Johnson, M.K., 2004. Implicit and explicit evaluation FMRI correlates of valence, emotional intensity, and control in the processing of attitudes. J. Cogn. Neurosci. 16, 1717-1729, http://dx.doi.org/10.1162/ 0898929042947919.

Cupchik, G.C., 1992. From perception to production: a multilevel analysis of the aesthetic process. In: Cupchik, G.C., Laszlo, J. (Eds.), Emerging Visions of the Aesthetic Process. Cambridge University Press, New York, NY, pp. 83-99.

Cupchik, G.C., Vartanian, O., Crawley, A., Mikulis, D.J., 2009. Viewing artworks contributions of cognitive control and perceptual facilitation to aesthetic experience. Brain Cogn. 70, 84-91, http://dx.doi.org/10.1016/j.bandc.2009.01. 003.

Cupchik, G.C., Winston, A.S., 1996. Confluence and divergence in empirical aesthetics, philosophy, and mainstream psychology. In: Carterette, E.C., Friedman, M.P. (Eds.), Cogntive Ecology. Academic Press, San Diego, CA, pp. $62-85$

Di Dio, C., Gallese, V., 2009. Neuroaesthetics: a review. Curr. Opin. Neurobiol. 19, 682-687, http://dx.doi.org/10.1016/j.conb.2009.09.001.

Di Dio, C., Macaluso, E., Rizzolatti, G., 2007. The golden beauty: brain response to classical and renaissance sculptures. PLoS ONE 2, http://dx.doi.org/10.1371/ journal.pone.0001201.

Di Dio, C., Canessa, N., Cappa, S.F., Rizzolatti, G., 2011. Specificity of esthetic experience for artworks: an fMRI study. Front. Hum. Neurosci. 5, 1-14, http:// dx.doi.org/10.3389/fnhum.2011.00139.

Downing, P.E., Jiang, Y., Shuman, M., Kanwisher, N., 2001. A cortical area selective for visual processing of the human body. Science 293, 2470-2473, http://dx. doi.org/10.1126/science.1063414.

Eickhoff, S.B., Laird, A.R., Grefkes, C., Wang, L.E., Zilles, K., Fox, P.T. 2009. Coordinate-based activation likelihood estimation meta-analysis of neuroimaging data: a random-effects approach based on empirical estimates of spatial uncertainty. Hum. Brain Mapp. 30, 2907-2926, http://dx.doi.org/10. 1002/hbm.20718.

Epstein, R., Harris, A., Stanley, D., Kanwisher, N., 1999. The parahippocampal place area: recognition, navigation, or encoding? Neuron $23,115-125$, http://dx.doi. org/10.1016/S0896-6273(00)80758-8.

Epstein, R., Kanwisher, N., 1998. A cortical representation of the local visual environment. Nature 392, 598-601

Flexas, A., Rosselló, J., de Miguel, P., Nadal, M., Munar, E., 2014. Cognitive control and unusual decisions about beauty: an fMRI study. Front. Hum. Neurosci. 8 , 1-9, http://dx.doi.org/10.3389/fnhum.2014.00520.

Greicius, M.D., Krasnow, B., Reiss, A.L., Menon, V., 2003. Functional connectivity in the resting brain: a network analysis of the default mode hypothesis. Proc. Nat Acad. Sci. U.S.A. 100, 253-258, http://dx.doi.org/10.1073/pnas.0135058100.
Hagtvedt, H., Patrick, V., 2008. The influence of art infusion on the perception and evaluation of consumer products. Adv. Consum. Res. 35, 795-796.

Ishizu, T., Zeki, S., 2013. The brain's specialized systems for aesthetic and perceptual judgment. Eur. J. Neurosci. 37, 1413-1420, http://dx.doi.org/10. $1111 /$ ejn.12135.

Ishizu, T., Zeki, S., 2011. Toward a brain-based theory of beauty. PLoS ONE 6, http:// dx.doi.org/10.1371/journal.pone.0021852.

Jacobsen, T., Schubotz, R.I., Höfel, L., Cramon, D.Y.V., 2006. Brain correlates of aesthetic judgment of beauty. Neuroimage 29, 276-285, http://dx.doi.org/10. 1016/j.neuroimage.2005.07.010.

Kant, I., 1790. Critique of judgment. In: Critique of Judgement., pp. 97-199, http:// dx.doi.org/10.1515/KANT.2007.020.

Kanwisher, N., McDermott, J., Chun, M.M., 1997. The fusiform face area: a module in human extrastriate cortex specialized for face perception. J. Neurosci. 17, 4302-4311, http://dx.doi.org/10.1098/Rstb.2006.1934.

Kawabata, H., Zeki, S., 2004. Neural correlates of beauty. J. Neurophysiol. 91, 1699-1705, http://dx.doi.org/10.1152/jn.00696.2003.

Kirk, U., Skov, M., Christensen, M.S., Nygaard, N., 2009a. Brain correlates of aesthetic expertise: a parametric fMRI study. Brain Cogn. 69, 306-315, http:/ dx.doi.org/10.1016/j.bandc.2008.08.004.

Kirk, U., Skov, M., Hulme, O., Christensen, M.S., Zeki, S., 2009b. Modulation of aesthetic value by semantic context: an fMRI study. Neuroimage 44, 1125-1132, http://dx.doi.org/10.1016/j.neuroimage.2008.10.009.

Lacey, S., Hagtvedt, H., Patrick, V.M., Anderson, A., Stilla, R., Deshpande, G., Hu, X. Sato, J.R., Reddy, S., Sathian, K., 2011. Art for reward's sake: visual art recruits the ventral striatum. Neuroimage 55, 420-433, http://dx.doi.org/10.1016/j. neuroimage.2010.11.027.

Leech, R., Sharp, D.J., 2014. The role of the posterior cingulate cortex in cognition and disease. Brain, http://dx.doi.org/10.1093/brain/awt162.

Marković, S., 2012. Components of aesthetic experience: aesthetic fascination, aesthetic appraisal, and aesthetic emotion. Iperception 3, 1-17, http://dx.doi. org/10.1068/i0450aap.

Mizokami, Y., Terao, T., Hatano, K., Kodama, K., Kohno, K., Makino, M., Hoaki, N. Araki, Y., Izumi, T., Shimomura, T., Fujiki, M., Kochiyama, T., 2014 Identification of the neural correlates of cyclothymic temperament using an esthetic judgment for paintings task in fMRI. J. Affect. Disord. 169, 47-50, http://dx.doi.org/10.1016/j.jad.2014.07.037.

Munar, E., Nadal, M., Castellanos, N.P., Flexas, A., Maestú, F., Mirasso, C. Cela-Conde, C.J., 2012. Aesthetic appreciation: event-related field and time-frequency analyses. Front. Hum. Neurosci. 5, 1-11, http://dx.doi.org/10 3389/fnhum.2011.00185.

Nadal, M., 2013. The experience of art. Insights from neuroimaging. Prog. Brain Res 204, 135-158, http://dx.doi.org/10.1016/B978-0-444-63287-6.00007-5.

Pessoa, L., 2008. On the relationship between emotion and cognition. Nat. Rev. Neurosci. 9, 148-158, http://dx.doi.org/10.1038/nrn2317.

Pöppel, E., Avram, M., Bao, Y., Graupmann, V., Gutyrchik, E., Lutz, A., Park, M., Reiser, M., Russell, E., Silveira, S., Smigielski, L., Szymanski, C., Zaytseva, Y., 2013. Sensory processing of art as a unique window into cognitive mechanisms: evidence from behavioral experiments and fMRI studies. Procedia -Soc. Behav. Sci. 86, 10-17, http://dx.doi.org/10.1016/j.sbspro.2013.08.517.

Rolls, E.T., Grabenhorst, F., 2008. The orbitofrontal cortex and beyond: from affect to decision-making. Prog. Neurobiol., http://dx.doi.org/10.1016/j.pneurobio. 2008.09.001.

Schopenhauer, A., 1969. The World as Will and Representation. Trans E. J. Payne, Trans., vol. 1. Dover, New York, NY

Taylor, J.C., Wiggett, A.J., Downing, P.E., 2007. Functional MRI analysis of body and body part representations in the extrastriate and fusiform body areas. J. Neurophysiol. 98, 1626-1633, http://dx.doi.org/10.1152/jn.00012.2007.

Tsakiris, M., Hesse, M.D., Boy, C., Haggard, P., Fink, G.R., 2007. Neural signatures of body ownership: a sensory network for bodily self-consciousness. Cereb. Cortex 17, 2235-2244, http://dx.doi.org/10.1093/cercor/bhl131.

Vartanian, O., Goel, V., 2004. Neuroanatomical correlates of aesthetic preference for paintings. Neuroreport 15, 893-897, http://dx.doi.org/10.1097/00001756200404090-00032.

Vartanian, O., Navarrete, G., Chatterjee, A., Fich, L.B., Leder, H., Modroño, C., Nadal M., Rostrup, N., Skov, M., 2013. Impact of contour on aesthetic judgments and approach-avoidance decisions in architecture. Proc. Natl. Acad. Sci. U.S.A. 110 (Suppl), 10446-10453, http://dx.doi.org/10.1073/pnas.1301227110.

Vartanian, O., Skov, M., 2014. Neural correlates of viewing paintings: evidence from a quantitative meta-analysis of functional magnetic resonance imaging data. Brain Cogn. 87, 52-56, http://dx doi.org/10.1016/j.bandc.2014.03.004.

Vessel, E.A., Starr, G.G., Rubin, N., 2012. The brain on art: intense aesthetic experience activates the default mode network. Front. Hum. Neurosci. 6, 1-17, http://dx.doi.org/10.3389/fnhum.2012.00066.

Yeh, Y., Lin, C.-W., Hsu, W.-C., Kuo, W.-J., Chan, Y.-C., 2015. Associated and dissociated neural substrates of aesthetic judgment and aesthetic emotion during the appreciation of everyday designed products. Neuropsychologia 73 , 151-160, http://dx.doi.org/10.1016/j.neuropsychologia.2015.05.010.

Zaidel, D.W., 2015. Neuroesthetics is not just about art. Front. Hum. Neurosci. 9, 80 http://dx.doi.org/10.3389/fnhum.2015.00080.

Zaidel, D.W., 2005. Neuropsychology of Art: Neurological, Cognitive, and Evolutionary Perspectives. Psychology Press, England, ISBN 10: 1841693634. 